\title{
Social netball - for fun, fitness and friends
}

\author{
Author: Sarah Reeves
}

\section{Aims}

To set up a student-organised social netball club to help support medical students as they transition into the clinical environment and move to a new locality.

\section{Methods}

> In June 2016, of the 60 students moving to the new locality, four formed a social netball committee.

> Weekly netball sessions began in September 2016. All abilities were encouraged; previous experience was recorded to facilitate appropriate drills.

> In term 1, the sessions were initially for women but in term 2 , men asked to join.

> Each term there were two social events and a tournament.

$>$ An end-of-year charity match against doctors was organised.

$>$ A register was taken at each session and informal feedback was obtained termly. An end-of-year membership survey was completed.

\section{Results}

The mean attendance in the first term was 14; in the second and third terms, it was 16 . Only four members had played regular netball before and 10 had never played. Socials were attended by a mean of 17 participants and tournaments by a mean of 32 .

The end-of-year survey was completed by 14 members and $100 \%$ said they intended to come next year, recommend to future cohorts and felt that the club had helped them settle into the new locality. This year the club has remained mixed, membership has increased to 30 students and it includes year 3, 4 and 5 students.

\section{Conclusions}

The success of the club and the good feedback suggest that the project achieved its objectives Studies have shown that stress levels are high in third-year medical students as they begin clinical years; similarly, change of locality is a recognised challenge. These year 3 students faced both. We were the second cohort at this locality and there were few student-led social activities in place. Our wellbeing and resilience were improved by the physical exercise and feeling part of something. During junior doctor training, trainees face similar challenges and part of professionalism is to manage these. Participation in the club has encouraged us to be involved in social and physical activities outside medicine as a way of managing work-life balance in the future. We need to establish funding to allow the club to continue to benefit future years.

\section{Conflict of interest statement}

I can confirm no conflict of interest. 